\title{
JUSTA FREIRE O LA PASIÓN DE EDUCAR. BIOGRAFÍA DE UNA MAESTRA ATRAPADA EN LA HISTORIA DE ESPAÑA (1896-1965),
}

\author{
por María del Mar del Pozo Andrés, \\ Barcelona, Octaedro, 346 páginas +32 de imágenes fotográficas.
}

ISBN: 978-84-9921-414-6.

Como una de tantas facetas de la crisis económica, que acompañan a otros fenómenos sociológicos, institucionales y académicos, asistimos, o eso sostienen tantas impresiones y observaciones repetidas en el ámbito de las instituciones universitarias concernidas, a un relativo empobrecimiento en cuanto a las posibilidades efectivas para el desarrollo investigador y la elaboración ensayística en el espacio de las ciencias sociales, lo que también afecta negativamente a la elaboración del conocimiento histórico y a su difusión social. «¿Qué fue de la Universidad?» se preguntaba José Luis Pardo en uno de sus cuidados textos periodísticos del pasado verano, al constatar que «se produce menos conocimiento —en términos de masa- y más descualificado». En este contexto y con preocupaciones similares, Nuccio Ordine desde Italia, en este caso con atención al campo de las humanidades hace, por su parte, una justa y crítica reclamación de la «utilidad de los inutil»; entiéndase de aquellos saberes que aparentemente no tienen una traducción económica determinable con el torpe sentido de inmediatez que en el presente padecemos.

Este panorama se pone de manifiesto en la actual menor producción editorial de textos históricos pertenecientes al género de las monografías de investigación con respecto a los años últimos del siglo Xx lo que, obedeciendo sin duda a variables económicas y sociológicas diversas, encuentra una de sus raíces en la menor elaboración de tales textos en el seno de nuestras Universidades, a su vez deudoras de las menores posibilidades efectivas para realizarlo, lo que es una dolorosa constatación. 
Ahora bien, hemos de entender que lo dicho no significa una general pérdida de creatividad académica, ya que junto a la menor elaboración y producción de textos como panorama general, asistimos igualmente a una apreciable floración, cierto que limitada en su número, de textos editados en esta modalidad de monografías de investigación y de ensayo histórico, construidos con alta calidad científica, muy atentos a los debates y varios «giros» historiogáficos abiertos internacionalmente y, además, expresados con considerables ejercicios literarios y de comunicación escrita. Lo dicho lo entendemos aplicable al campo sectorial de la historiografía educativa elaborada en España.

El presente libro de la profesora María del Mar del Pozo Andrés es uno de estos textos, para beneficio tanto de la comunidad científica, como del conjunto de lectores y lectoras. Desechando cualquier gramo de inmediatez, en bien de la calidad científica y académica, es como se ha construido por parte de dicha investigadora esta «escritura biográfica», en la que se habla de la vida comprometida, siempre vital y optimista, de una maestra de la escuela pública, Justa Freire, que llevó a cabo buena parte de su ejercicio docente y educador a lo largo de los pasados años veinte-treinta, cuando se abrían luces de alba oteadas desde los más dispares horizontes de la realidad española, y cuando, como nunca anteriormente, un número creciente de mujeres se incorporaban a la vida social y cívica como nuevas actrices de la construcción social. Vida y oficio educador el de Justa Freire, que se vio profundamente relacionado con el de otros maestros y profesores de la época, en un tiempo que parecía invitar a la búsqueda de horizontes de progreso social y democrático, en el que se vieron conscientemente implicadas un creciente número de maestras y profesoras, al punto de hablarse hoy, de modo parecido a como en su día se hizo con respecto a los varores, de las «maestras de la República». Justa Freire era en plenitud una de ellas, aunque por ello mismo se vió agriamente atrapada en los azares de la sociedad franquista.

Hablamos de aquellas maestras y profesoras que además de alcanzar una mejor formación cultural, pedagógica y profesional, lograda a través de las reformas de 1914 en los planes de estudios de las Escuelas Normales o del papel desempeñado por la Escuela Superior del Magisterio, vivieron con intensidad en el día a día con los niños y niñas, con los padres, o con sus compañeros, su compromiso docente educador, incorporando en ello y en su presencia cívica los valores e ideales más propicios a la igualdad, la 
justicia y la solidaridad, aquellos que sin duda dieron sustento a los mejores proyectos, discursos y prácticas políticas de la II República.

Maestras y profesoras que habían pasado desapercibidas, hacia las que más recientemente se ha dirigido nuestra mirada bajo incitación, sin duda, de mujeres investigadoras. En esta mirada, !cuánto habrá tenido que ver Josefina Aldecoa, la directora del Colegio Estudio de Madrid, memoria viva de la Institución Libre de Enseñanza, y en particular autora en 1990 de Historia de una maestra!. Y afortunadamente no solo ella. La aún reciente construcción de la arquitectura de derechos constitucionales en España, y tantos otros elementos, muchos de ellos intangibles, como la apertura a la elaboración de una nueva historia social asentada en la antropología histórica, o la revisión de la historia de la contrucción de «lo femenino», tan presente en los gender studies, propiciaban girar la mirada. En 1991 Michelle Perrot y George Duby, los Annales una vez más, abrían paso a la fundamental y voluminosa Histoire des femmes en Occident (en la prestigiosa Plon de París, para los estudios históricos). La Sociedad Española de Historia de la Educación celebraba un año antes su VI Coloquio Español de Historia de la Educación con la temática Mujer y Educación en la España contemporánea (Santiago de Compostela, 1990) con textos, entre otros, como los de Geraldine Scanlon\&Rosa Capel (educación de la mujer y Edad de Plata), Antonio Viñao o Pilar Ballarín. En el mismo año aparecía otro libro luminoso, con su casi infinita riqueza de datos, si de maestras de la República hablamos, el de Teresa Marín Eced, La renovación pedagógica en España (1907-1936). Los pensionados en pedagogía por la Junta de Ampliación de Estudios. Pocos años más tarde, desde Francia, nos llegaba la revista de estudios Clio. Histoire, Femmes et Societes (1995), que quizás haya podido incitar la aparición de nuestra Arenal. Revista de historia de las mujeres con el necesario apoyo institucional de la Universidad de Granada, que dispone al día de hoy de una consistente trayectoria. Se vendrían a sumar los balances historiográficos de Françoise Thébaud de 1998, Écrire l'histoire des femmes, en 2004 renovados con un título revisado: Écrire l'histoire des femmes et du genre. Mientras, entre nosotros, más acá de los estudios de Mary Nash y de Sonsoles San Roman, aparecían los de Consuelo Flecha y de Pilar Ballarín, hasta llegar a los más recientes.

A María Sánchez Arbós (!alma, María, alma!... le decía Cossío), que había publicado en el exilio de México en 1961 su testimonio de educadora tan profundamente institucionista en Mi diario (1918-1961), un texto practica- 
mente desconocido entre nosotros hasta la impagable edición aragonesa (2006) con una introducción de Victor Juan Borroy y Antonio Viñao, entre otras numerosas, destacadas y profundas educadoras de espíritu republicano, como la gallega María Barbeito, figura también recientemente estudiada con atención por parte de Ana Romero Massiá y en espera de una edición gallega, se une ahora con fuerza y singularidad el nombre de Justa Freire, "protagonista de una historia de amor y de apasionamiento por la escuela y por la enseñanza» — como indica la profesora Mar del Pozo—, tejida con los mimbres de una práctica profesional siempre reflexiva y reflexionada. Casi al mismo tiempo Raquel Vázquez Ramil nos sirve Mujeres y Educación en la España contemporánea. La Institución Libre de Enseñanza y la Residencia de Señoritas de Madrid (2012), lo que para el caso valenciano hizo Carme Agulló con su texto «Breus apunts al voltant de les mestres valencianes republicanes i les revistes escolars». Todo un conjunto de aportaciones que, de algún modo, vinieron a confluir en el texto colectivo Las maestras de la República (2012), bajo edición de Elena Sánchez de Madariaga, y en el documental del mismo título dirigido por Pilar Pérez Solano, auspiciado por FETE-UGT, que en la reciente convocatoria (2014) de los Premios cinematográficos Goya ha merecido un especial reconocimiento, que es muestra de agradecimiento también a las investigadoras de historia de la educación que lo han hecho posible, una de ellas la profesora María del Mar del Pozo.

Su texto sobre Justa Freire, que suscita aquí este comentario, está elaborado con rigor y belleza, como han señalado desde la Fundación Angel Llorca, al apadrinar la cuidada edición. Desde el necesario hilo cronológico, la autora, trenzando notas escritas, entrevistas (realizadas aquí y allá), imágenes, sospechas, hipótesis, y con un buen manejo de escenarios socio-políticos y de categorías analíticas e interpretativas, nos permite acceder a una memoria hecha historia ("un yo unido a las circunstancias»), al tiempo que «acerca a la mirada del lector actual todo un mundo que le precede», en medio de un retrato caleidoscópico de una parte de la historia de España. Una historia de vida que es como «una mediación entre la historia individual y la social». Al construirla y narrarla, se hace un ejercicio historiográfico en el que se ponen en juego la microhistoria, algunas de las categorías centrales de la historia cultural, la superación de las limitaciones de la historia estructural, y la calidad narrativa.

Quiero llamar la atención sobre la tensión entre biografía e historia. El estructuralismo y las corrientes ortodoxas del marxismo (casi) habían 
arrumbado el género biográfico histórico. Bien entendemos el por qué si tenemos en cuenta las deudas de este género con el historicismo y con la «historia nacional tradicional». Fue necesario hacer revisión de cuentas. François Dosse lo procuró con su Le pari biographique. Écrire une vie (2005). Hoy podemos asistir a un feliz reencuentro entre historia y biografía, como ha tenido ocasión de escribir Marc Ferro, una vez que la acción humana y las vidas son interrogadas en cuanto a su sentido, sus tensiones, o sus contradicciones, aún sabiendo que desde la más exigente elaboración hermenéutica del texto histórico no se podrá llegar a todas las teclas de la intencionalidad humana de la biografía examinada.

Volvemos sobre Justa Freire, a quien se dedican 300 páginas para el relato interpretativo de una vida, mediante una distribución en 25 capítulos, cada uno de ellos de entre diez a quince páginas, con el acompañamiento de un selecto, rico y variado archivo fotográfico: la vida de una maestra de vanguardia que se inscribe desde los primeros años veinte del pasado siglo en los mejores ideales culturales y sociales de la Escuela Nueva, siguiendo la estela de su cercano maestro Angel Llorca, figura sobre la que Mar del Pozo se había detenido anteriormente. Desde un origen humilde que se sitúa en la población zamorana de Moraleja del Vino, aunque presidido por un amor singular a la lectura, el periplo vital de Justa Freire le lleva de Zamora, una vez realizados los estudios de Magisterio, a Madrid, en donde, antes de empezar a ejercer como maestra (años 1917 y 1918), comenzará a relacionarse con un sector muy destacado del profesorado madrileño, lo que le permitirá incorporarse a «una generación de docentes muy bien preparados culturalmente y casi todos vocacionales y europeistas convencidos». Casi a las puertas de su incorporación al colegio institucionista de Sierra Pambley en Villablino, en relación con Cossío, su destino como maestra pública le conducirá a una escuelita rural en la sierra de Gredos, antes de ser seleccionada en 1921 para incorporarse al equipo docente del innovador y experimental Grupo Escolar «Cervantes» de Madrid, donde permanecerá hasta que en 1933 se convierta en la Directora del Grupo escolar «Alfredo Calderón», también fuertemente renovador, donde permanecerá hasta el tiempo de la guerra y del Madrid asediado, momento en el que su labor, después de la experiencia con las colonias infantiles de los grupos escolares, se llevará a cabo en las Comunidades Familiares de Educación situadas en la provincia de Valencia. Vendrán luego: su ingreso en la cárcel de mujeres de Ventas hasta mediados de 1941, y a continuación el exilio interior como el de tantas 
compañeras y amigos (una generación «tronchada»), las clases particulares, la entrada como secretaria y a continuación como docente en el (católico) Colegio Británico de Madrid, el doble calvario de la rehabilitación y la posibilidad del reingreso (1953) «en ningún caso en Madrid»: tan lejos para ella como Manresa, bien que al fin, en 1962, parece terminar su «invisibilidad», al abrírsele tenuamente las puertas de El Magisterio Español. Escasamente tres años antes de su muerte.

Una vida en la que anotamos la preocupación por la didáctica, por las didácticas especializadas, su capacidad de liderazgo organizativo puesta a prueba en el Grupo Escolar «Alfredo Calderon», su conciencia de servicio público, que se extiende a su actuación como educadora en colonias escolares desde 1923, su conciencia profesional desde la que se incorpora en 1921 a la Asociación General de Maestros, que desembocará en la FETE a la que siempre pertenecerá, o su fuerza como «maestra de maestras». Era también una maestra de "diario», de continuas notas escritas, afortunadamente guardadas con cariño por parte de su hija adoptiva, Carmen Cabello, y entregadas a la Fundación Angel Llorca, donde Mar del Pozo ha podido revisarlas con atención.

Una historia de vida que, por ejemplo, nos permite el acercamiento a la historia (interna) de las aulas, a la historia de los desarrollos, creaciones y apropiaciones curriculares suscitadas en dos grupos escolares. Nos aproxima a la «visibilidad» de la vida de grupo de sus equipos docentes, tanto en el día a día, como en situaciones específicas, como las de los viajes de estudios a Europa (Heildelberg, Ginebra). Historia cotidiana, exilio interior, el calvario del reingreso con sus innumerables gestiones. La vida escolar en un colegio de elite como el Colegio Británico. El paso del laicismo consciente a la creencia católica. Un haz de páginas, que cierran la indicación de fuentes y pertinentes índices, de todo punto muy valiosas en nuestra historia contemporanea de la educación.

Antón Costa Rico

Universidad de Santiago de Compostela anton.costa@usc.es 